\title{
Regulation of ABCG2 expression by Wnt5a through FZD7 in human pancreatic cancer cells
}

\author{
ZHONGBO ZHANG $^{1}$, SHUANG GAO $^{2}$, YUANHONG XU $^{1}$ and CHENGHAI ZHAO ${ }^{3}$ \\ ${ }^{1}$ Department of Pancreatic and Biliary Surgery, The First Hospital of China Medical University, Shenyang, Liaoning 110001; \\ ${ }^{2}$ Department of Bioengineering, College of Life Science, North China University of Science and Technology, \\ Tangshan, Hebei 063000; ${ }^{3}$ Department of Pathophysiology, Basic Medical College, \\ China Medical University, Shenyang, Liaoning 110001, P.R. China
}

Received July 23, 2020; Accepted October 20, 2020

DOI: $10.3892 / \mathrm{mmr} .2020 .11690$

\begin{abstract}
ATP-binding cassette subfamily G member 2 (ABCG2), a member of the ABC transporter superfamily, has been implicated in the development of chemotherapeutic drug resistance in cancer cells. However, the regulators of ABCG2 expression and their roles in anticancer drug resistance have not been fully characterized, especially in the context of pancreatic cancer. The aim of the present study was to investigate whether ABCG2 contributed to drug resistance in pancreatic cancer and to elucidate its regulatory molecular pathways. Using immunohistochemical analysis of pancreatic ductal adenocarcinoma and adjacent healthy tissue samples, the present study identified a positive correlation between ABCG2 and Wnt5a, a member of the Wnt family of secreted proteins. It was also determined that treatment with recombinant human Wnt5a protein could upregulate the expression of ABCG2 in the Capan-2 human pancreatic cancer cell line and enhance its resistance to gemcitabine. The upregulation of ABCG2 by Wnt5a was inhibited by small interfering RNA silencing of Frizzled class receptor 7 (FZD7) or by FZD7 inhibitors. Moreover, both FZD7 silencing or inhibition of its function attenuated gemcitabine resistance induced by Wnt5a in Capan- 2 cells. Therefore, the present findings suggested that Wnt5a and FZD7 acted as upstream regulators of ABCG2 expression and that FZD7 may be an essential factor for Wnt5a-induced gemcitabine resistance in pancreatic cancer cells.
\end{abstract}

Correspondence to: Professor Yuanhong $\mathrm{Xu}$, Department of Pancreatic and Biliary Surgery, The First Hospital of China Medical University, 155 Nanjing North Street, Heping, Shenyang, Liaoning 110001, P.R. China

E-mail: 13504997289@163.com

Dr Chenghai Zhao, Department of Pathophysiology, Basic Medical College, China Medical University, 77 Puhe Road, Shenyang North New Area, Shenyang, Liaoning 110001, P.R. China

E-mail: zhaochenghai@sina.com

Key words: ABCG2, Wnt5a, FZD7, pancreatic ductal adenocarcinoma, gemcitabine resistance

\section{Introduction}

Pancreatic ductal adenocarcinoma (PDAC) accounts for $80-90 \%$ of pancreatic tumors and is the 4th most common cause of cancer-related mortality in the USA. Moreover, its 5 -year survival rate is $<5 \%$, with a median survival time of $<6$ months. Surgical resection and chemotherapy are the main approaches to the treatment of pancreatic cancer; however, $<20 \%$ of patients are eligible for surgery at diagnosis (1). For patients with pancreatic cancer with locally advanced or metastatic tumors, chemotherapy is the standard treatment. Gemcitabine (Gem) has been used as a first-line treatment for patients with pancreatic cancer since the late 1990s (2). However, the sensitivity of pancreatic cancer to Gem is poor. Therefore, understanding the mechanisms of Gem resistance is important for the effective treatment of pancreatic cancer.

Among several proposed mechanisms that mediate acquired Gem resistance in patients with pancreatic cancer, one possible mechanism is drug efflux via ATP-binding cassette (ABC)-transporters (3-5). ABC-transporter superfamily proteins contribute to multidrug resistance (MDR) by transporting the substrates of anticancer drugs out of cancer cells, ultimately decreasing their intracellular accumulation (6). MDR in cancer is a condition in which cancer cells become resistant to structurally-unrelated anticancer drugs (7). Among ABC transporters, ABC subfamily B member 1 (ABCB1), C member 1 (ABCC1) and $\mathrm{G}$ member 2 (ABCG2), are strongly associated with MDR $(8,9)$. It has been reported that the increase in ABCG2 protein expression is essential for Gem resistance in pancreatic cancer cells (10), but the underlying mechanisms that regulate $\mathrm{ABCG} 2$ expression are yet to be elucidated.

Previous studies have suggested that the Wnt/ $\beta$-catenin signaling pathway may be an upstream molecular mechanism regulating the expression of ABCG2 (11-14). In lung cancer cell lines, cisplatin can indirectly affect the expression of ABCG2 by changing the expression of $\beta$-catenin (11). microRNAs are reported to enhance cisplatin resistance in colon cancer cells by increasing the expression of ABCG2 through Wnt proteins (12). Furthermore, cisplatin, methotrexate and doxorubicin can upregulate the expression of ABCG2, and also activate the Wnt/ $\beta$-catenin pathway, thus inducing MDR in 
osteosarcoma during chemotherapy (13). In acute and chronic liver diseases, the Wnt pathway also upregulates the expression of ABCG2 in liver tissue (14).

Among a large class of secreted Wnt proteins, Wnt5a has been identified as a biomarker of poor clinical outcome in patients with ovarian cancer, as well as a mediator of chemoresistance (15). Upregulated expression levels of cellular Wnt5a and secreted Wnt5a are observed in multidrug-resistant KB-V1, NCI/ADR-RES and SW620-MDR1 cells of the cervix, ovaries and colon, respectively (16). Elevated expression of Wnt5a regulates the Wnt signaling pathway to support cancer cell resistant to chemotherapy (16). Moreover, in in vitro experiments using the bladder cancer cell lines UM-UC-3 and SW780, the drug resistance of UM-UC-3a cells to Gem increased after the overexpression of Wnt5a protein, while the drug resistance of SW780 cells to Gem decreased wwith Wnt5a downregulation (17). In addition, inhibition of Wnt5a leads to significant increases in the drug-induced apoptosis of pancreatic cancer cells, both in vitro and in vivo (18).

The aim of the current study was to investigate the upstream regulators of $\mathrm{ABCG} 2$ expression and their roles in Gem resistance in pancreatic cell lines. It was identified that ABCG2 was upregulated by Wnt5a through the upregulation of Frizzled class receptor 7 (FZD7), a receptor involved in Wnt signaling. Importantly, FZD7 was required for Wnt5a-induced resistance of pancreatic cancer cells to Gem treatment. Thus, the present findings may provide insight into the mechanisms of drug-resistance in pancreatic cancer.

\section{Materials and methods}

Human pancreatic cancer specimens. A total of 24 patient pancreatic cancer specimens and adjacent para-carcinoma tissue specimens were obtained from the Department of Pancreatic and Biliary Surgery, China Medical University. All patients provided written consent to undergo curative surgical resection and 30-months follow-up and to the use of their samples for research. The present study was approved by the Ethics Committee of The First Hospital of China Medical University. All patients with pancreatic ductal adenocarcinoma (PDAC) were diagnosed by a certified pathologist according to the WHO guidelines. The pathological TNM stage was assessed according to the criteria of the 6th edition of the TNM classification of the American Joint Committee on Cancer (AJCC). All 24 patients were in stage Ia-IIb, according to the AJCC criteria, and underwent radical excision operation. ABCG2 expression did not correlate with sex, age or TNM stage, but correlated with histological grade (Table I).

Immunohistochemistry (IHC). The PDAC tissue was immediately cut into small pieces and placed in $4 \%$ paraformaldehyde for fixation at room temperature for $12 \mathrm{~h}$, and then paraffin embedded. IHC analysis was performed on 4-6 $\mu \mathrm{m}$ paraffin sections of human PDAC tissues. Xylene and gradient alcohols were used to deparaffinize and hydrate, respectively. Then, $3 \% \mathrm{H}_{2} \mathrm{O}_{2}$ was added to the sections to remove endogenous peroxidase. Sections were incubated with citrate buffer to repair antigen, and blocked with BSA (5\%; Sangon Tech Co., Ltd.; cat. no. A600332) at $4^{\circ} \mathrm{C}$ for 30 mins. Primary antibodies were used as follows: ABCG2 (1:400; Cell Signaling Technology,
Inc.; cat. no. 42078) and Wnt5a (1:300; Cell Signaling Technology, Inc.; cat. no. 2530). After incubation with primary antibodies overnight at $4^{\circ} \mathrm{C}$ in a wet box, incubated with horseradish peroxidase-conjugated secondary antibody (1:2,000; Invitrogen; Thermo Fisher Scientific, Inc.; cat. no. 31460) at room temperature for $30 \mathrm{~min}$. Diaminobenzidine (Boster Biological Technology) was used at room temperature for 10-20 min to stain the sections dissolved in Tris- $\mathrm{HCl}$ and $\mathrm{H}_{2} \mathrm{O}_{2}$. Then, sections were re-stained in hematoxylin at room temperature for 5-15 sec, dehydrated with gradient alcohol and xylene and sealed with cover slides. The images were captured under a light microscope at $\mathrm{x} 40$ magnification.

The percentage of positive cells was divided into five grades (percentage scores): i) $0,<10 \%$; ii) $1,10-25 \%$; iii) $2,25-50 \%$; iv) $3,50-75 \%$; and v) $4,>75 \%$. In addition, the intensity of staining was divided into four grades (intensity scores): i) 0 , No staining; ii) 1 , light brown; iii) 2 , brown; and iv) 3 , dark brown. ABCG2/Wnt5a staining positivity was evaluated using IHC scores, which were calculated as: IHC score=percentage score $\mathrm{x}$ intensity score. Thus, based on the percentage and intensity scores, target protein staining was classified into four groups: i) IHC score $\leq 3$, negative; ii) IHC score $>3$ and $\leq 6$, weak; iii) IHC $>6$ and $\leq 9$, moderate; and iii) IHC $>9$, strong (19).

Survival analysis was performed by comparing the postoperative survival time of all ABCG2 positive specimens (IHC scores $>3$ and $\leq 12$, weak to strong positives) and negative specimens (IHC scores $\leq 3$, negative) using GraphPad Prism version 7.0. Spearman's correlation analysis was conducted between Wnt5a and FZD7 IHC scores in 24 specimens. In addition, specimens of deceased patients were scored according to postoperative survival time: 0-2 months were set as 1, 3-5 months as 2, 6-8 months as 3, and so on. Then, a Spearman's correlation analysis was conducted between this survival scores and ABCG2 IHC scores. Spearman's correlation analysis was conducted using SPSS 22.0 software (IBM Corp.). $\mathrm{P}<0.05$ was considered to be statistically significant difference.

Cell culture. Human pancreatic carcinoma cell lines, Capan-2, Panc-1, SW1990 and AsPC-1, were purchased from American Type Culture Collection. All cell lines were cultured and maintained in DMEM (Gibco; Thermo Fisher Scientific, Inc.) supplemented with 10\% FBS (cat. no. CCS30009.02; MRC Biotechnology Co., Ltd.; http://www.mrcing.com/pd.jsp?id=7), $100 \mathrm{U} / \mathrm{ml}$ penicillin and $100 \mu \mathrm{g} / \mathrm{ml}$ streptomycin. Cells were incubated at $37^{\circ} \mathrm{C}$ in a humidified atmosphere containing $5 \% \mathrm{CO}_{2}$. Recombinant human Wnt5a (rhWnt5a) was purchased from R\&D Systems, Inc. (cat. no. 645-WN-010).

Transient transfection. The FZD7-expressing plasmid and small interfering (si)RNA targeting FZD7, as well as the control vector and control siRNA, were purchased from Jikai Gene Technology Co., Ltd (cat. no. GIEE0156818). The targeting sequences of FZD7 siRNAs were as follows: i) siFZD7-1; 5'-AGTACCTGATGACCATGAT-3'; ii) siFZD7-2, 5'-AGC CGTACCACGGAGAGAA-3'; and iii) siFZD7-3, 5'-GTT CGTCTACCTCTTCATA-3'. Transfection was performed using Lipofectamine ${ }^{\mathrm{TM}} 3000$ (Invitrogen; Thermo Fisher Scientific, Inc.), according to the manufacturer's instructions. Capan- 2 cells were seeded at $1 \times 10^{6}$ cells/well into 6 -well plates 
Table I. Relationship between ABCG2 expression and clinicopathological characteristics of patients with pancreatic ductal adenocarcinoma.

\begin{tabular}{|c|c|c|c|c|}
\hline \multirow[b]{2}{*}{ Clinicopathological characteristic } & \multirow[b]{2}{*}{ Total cases, $\mathrm{n}$} & \multicolumn{2}{|c|}{ ABCG2 expression $n(\%)$} & \multirow[b]{2}{*}{ P-value } \\
\hline & & Negative & Positive & \\
\hline Sex & & & & 0.431 \\
\hline Male & 13 & $4(16.7)$ & $9(37.5)$ & \\
\hline Female & 11 & $7(29.2)$ & $4(16.7)$ & \\
\hline Median age & & & & 0.341 \\
\hline$\leq 55$ & 9 & $3(12.5)$ & $6(25.0)$ & \\
\hline$>55$ & 15 & $8(33.3)$ & $7(29.2)$ & \\
\hline Histological grade & & & & 0.027 \\
\hline Good & 7 & $6(25.0)$ & $1(4.2)$ & \\
\hline Moderate & 7 & $3(12.5)$ & $4(16.7)$ & \\
\hline Poor & 10 & $2(8.3)$ & $8(33.3)$ & \\
\hline AJCC TNM stage & & & & 0.248 \\
\hline IA & 5 & $3(12.5)$ & 0 & \\
\hline IB & 4 & $2(8.3)$ & $4(16.7)$ & \\
\hline IIA & 9 & $4(16.7)$ & $6(25.0)$ & \\
\hline IIB & 6 & $2(8.3)$ & $3(12.5)$ & \\
\hline pT status & & & & 0.389 \\
\hline $\mathrm{T} 1$ & 6 & $4(16.7)$ & $2(8.3)$ & \\
\hline $\mathrm{T} 2$ & 7 & $2(8.3)$ & $5(20.8)$ & \\
\hline $\mathrm{T} 3$ & 11 & $5(20.8)$ & $6(25.0)$ & \\
\hline pN status & & & & 0.813 \\
\hline No & 18 & $8(33.3)$ & $10(41.7)$ & \\
\hline N1 & 6 & $3(12.5)$ & $3(12.5)$ & \\
\hline
\end{tabular}

${ }^{\mathrm{a}} \chi^{2}$ test. ABCG2, ATP binding cassette subfamily G member 2; AJCC, American Joint Committee on Cancer.

12-18 $\mathrm{h}$ prior to transfection. According protocol, when cells were $70-80 \%$ confluent, a mixture of $2,500 \mathrm{ng}$ siRNA and $6 \mu$ l Lipofectamine ${ }^{\mathrm{TM}} 3000$ regent was added per well. A total of $6 \mathrm{~h}$ after transfection, the medium was replaced with complete medium and intervention reagents were added to culture medium, as indicated. Cells were collected after $48 \mathrm{~h}$ of additional culture.

Western blot analysis. Capan-2 cells were lysed in cold RIPA lysis buffer (Beyotime Institute of Biotechnology) and quantified using the BCA method. Subsequently, the proteins $(25 \mu \mathrm{g}$ of protein loaded per lane) were separated by SDS-PAGE using $8 \%$ gels, then transferred to a PVDF membrane. The membranes were blocked in 5\% non-fat dried milk in TBS-Tween 20 for $2 \mathrm{~h}$ at room temperature and then incubated overnight with specific primary antibodies against ABCG2 (1:1,000; Cell Signaling Technology, Inc.; cat. no. 42078), Wnt5a (1:1,000; Cell Signaling Technology, Inc.; cat. no. 2530) and FZD7 (1:1,000; Abcam; cat. no. ab64636) at $4^{\circ} \mathrm{C}$. GAPDH (1:10,000; ProteinTech Group, Inc.; cat. no. HRP-60004) was used as a control. After incubation with horseradish peroxidase-conjugated secondary antibody (1:10,000; Invitrogen; Thermo Fisher Scientific, Inc.; cat. no. 31460) for $2 \mathrm{~h}$ at room temperature. SuperSignal Chemiluminescent Substrates
(Thermo Fisher Scientific, Inc.) and imaging systems were used to collect the results. ImageJ (ImageJ v1.8.0; National Institutes of Health) was used for densitometry.

MTT assay. Cells were incubated at $37^{\circ} \mathrm{C}$ in a humidified atmosphere containing $5 \% \mathrm{CO}_{2}$ as aforementioned, and plated at a density of 20,000 cells/well in 96-well plates, then divided into several groups: Capan-2 vs. Capan-2 treated with rhWnt5a; conCapan-2 treated with rhWnt5a vs. siFZD7-Capan-2 treated with rhWnt5a; Capan-2 vs. Capan-2 treated with rhWnt5a and recombinant human Frizzled-7 Fc Chimera (rhFc, a recombinant human immunoglobulin that can bind to the Fzd7 molecule and blocks its biological activity, so that it loses its normal function; R\&D Systems, Inc.; cat. no. 6178-FZ-050) together. Capan-2 cells were cultured with rhWnt5a for $12 \mathrm{~h}$ prior Gem (Eli Lilly and Company) treatment. Concentrations of Gem range from 0-10 $\mu \mathrm{M}$. Drug resistance was examined $48 \mathrm{~h}$ after Gem treatment using an MTT assay. A total of $4 \mathrm{~h}$ after the addition of MTT to the culture medium, formazan was dissolved using DMSO, fluorescence was measured using a microplate reader at a wavelength of $570 \mathrm{~nm}$.

Flow cytometry assay for cell apoptosis analysis. Cells were detached and labeled using an Annexin V-PE/7-AAD 
apoptosis detection kit (cat. no. KGA1015-1018; Nanjing KeyGen Biotech Co., Ltd.), according to manufacturer's instructions. Apoptotic and necrotic cells were quantified using a flow cytometer (BD Accuri ${ }^{\mathrm{TM}} \mathrm{C} 6$; BD Biosciences) and the BD Accuri C6 Plus 1.0.23.1 software (BD Biosciences) was used for analysis. A total of 20,000 cells were analyzed for each sample. Cells negative for Annexin V-PE and 7-AAD were considered viable. Cells with Annexin $\mathrm{V}_{-} \mathrm{PE}^{+}$and 7-AAD staining were indicative of early apoptosis, while Annexin $\mathrm{V}-\mathrm{PE}^{+}$and $7-\mathrm{AAD}^{+}$cells were considered as late apoptotic and necrotic cells.

Establishment of Gem-resistant cell lines. PDAC cells were continuously treated with a low concentration of Gem to obtain drug-resistant cell line (20), such as the AsPC-1/Gem, Capan-2/Gem and Panc-1/Gem Gem-resistant cell lines. Cells were incubated at $37^{\circ} \mathrm{C}$ in a humidified atmosphere containing $5 \% \mathrm{CO}_{2}$ as aforementioned. First, the $\mathrm{IC}_{50}$ of $\mathrm{Gem}$ was measured for the parental cells using MTT assay, then $1 / 8$ of the $\mathrm{IC}_{50}$ for parental cells was designated as the initial induction concentration. After $24 \mathrm{~h}$, the culture medium was changed, and culture was continued until the cells reached $70-80 \%$ confluent. Then, adherent cells were digested and passaged. Cells were cultured in a medium containing a higher concentration of Gem $\left(1 / 4 \mathrm{IC}_{50}\right)$ after subculture. This was repeated several times, as Gem concentration reached above $\mathrm{IC}_{50}$. The cells were maintained in normal culture and frozen. After 3 days, cells were thawed and cultured with medium containing $\mathrm{Gem}$ at $\mathrm{IC}_{50}$. Cells were observed under a light microscope, if cells grew well, the drug-resistant cell lines were considered established.

Statistical analysis. All data presented as the mean \pm SD of three independent experiments. The association between FZD7 expression and clinicopathological characteristics was analyzed using a $\chi^{2}$ test. Statistical evaluation of continuous data was performed using one-way ANOVA followed by Tukey's post hoc test for multigroup comparisons, or a paired $t$-tests for comparison of differences between two groups. Wilcoxon's signed rank test was used to analyze the IHC data using SPSS 22.0 software (IBM Corp.), the Spearman's correlation analysis was conducted between Wnt5a and FZD7 IHC scores using SPSS 22.0 software (IBM Corp.). Survival analysis was carried out using GraphPad Prism version 7.0 (GraphPad Software, Inc.). P $<0.05$ was considered to indicate a statistically significant difference.

Bioinformatics analysis. Correlation analysis of gene expression was performed using 'R2: Genomics Analysis and Visualization Platform' (https://hgserverl.amc.nl/) (21). The correlation analysis of Wnt5a vs. ABCG2 was performed in data set of 'Tumor Colon CRC cell pop.-Calon-24-MAS5.0-u133p2', 'Tumor Lymphoma (T-cell Angioimmunoblastic)-Te h-20-MAS5.0-u133p2', 'Exp Glioblastoma 5aza-dC drug-Mueller-12-MAS5.0-u133a', 'Tumor Wilms VLRWT-Perlman-39-MAS5.0-u133a' and 'Mixed Pancreatic-K anai-22-MAS5.0-u133p2'. The correlation analysis of Wnt5a vs. FZD7 andFZD7 vs. ABCG2 were performed in dataset of 'Tumor Pancreatic adenocarcinoma-TCGA-178-rsem-tcgars', 'Tumor Pancreatic ductal adenocarcinoma-Yeh-132-custom-4hm44k' and 'Tumor Pancreatic ductal adenocarcinoma (ICGC)-Perez-91-complex-ilmnht12v4'.

\section{Results}

ABCG2 is expressed in human pancreatic cancer tissues. To determine the protein expression levels of ABCG2 and Wnt5a in human pancreatic cancer tissue, IHC was performed on 24 PDAC and matched para-carcinoma tissue specimens. IHC results confirmed that Wnt5a and ABCG2 were expressed in different degrees in pancreatic cancer tissues (Fig. 1A) of the 24 PDAC samples, IHC scores for ABCG2 ranged between 4-12 in 13 cases, giving a positive rate of 54.2\%. The IHC scores for Wnt5a ranged between 4-12 in 14 cases, giving a positive rate of 58.3\%. The expression levels of ABCG2 and Wnt5a genes were significantly higher in the PDAC tissues compared with adjacent tissues (Fig. 1B). The Spearman's correlation coefficient between ABCG2 and Wnt5a expression levels in the 24 PDAC specimens reached 0.692 , suggesting a positive correlation between Wnt5a and ABCG2 expression (Fig. 1C).

Survival analysis demonstrated the high ABCG2 expression group displayed significantly lower probability of survival, compared with the low-expression group (Fig. 1D). While the postoperative survival time of the 24 cases ranged between 3-26 months, the median survival time of ABCG2 group (11 cases) and $\mathrm{ABCG}^{+}$group (13 cases), were 17 months and 9 months, respectively (Table I). Moreover, the ABCG2 IHC scores in deceased patients negatively correlated with the postoperative survival time, with a Spearman's coefficient of -0.819 (Fig. 1E).

Wnt5a protein expression is positively correlates with $A B C G 2$. To further determine the association between Wnt5a and ABCG2 expression levels, The correlation analysis of Wnt5a and ABCG2 was performed using the gene correlation module of the R2 microarray analysis and visualization platform, which identified that the expression levels of Wnt5a and ABCG2 were positively correlated in colon cancer (data set of 'Tumor Colon CRC cell pop.-Calon-24-MAS5.0-u133p2'), lymphoma [data set of 'Tumor Lymphoma (T-cell Angioimmunoblastic)-Teh-20 -MAS5.0-u133p2'], glioma (data set of 'Exp Glioblastoma 5aza-dC drug-Mueller-12-MAS5.0-u133a') and nephroblastoma (data set of 'Tumor Wilms VLRWT-Perlman-39-MA S5.0-u133a'), with a Pearson correlation coefficient ranging between 0.643-0.83 (Fig. 2A). The Pearson coefficient was 0.377 in mixed pancreatic diseases (data set of 'Mixed Panc reatic-Kanai-22-MAS5.0-u133p2') (Fig. 2B), suggesting a moderate correlation between the expression levels of Wnt5a and ABCG2 in pancreatic diseases.

To examine the expression of Wnt5a and ABCG2 in human pancreatic cancer, the protein expression levels for Wnt5a and ABCG2 in four different types of pancreatic cancer cell lines were measured using western blotting. SW1990 and PANC-1, which had higher expression levels of WNT5a, also expressed ABCG2 at relatively high level (Fig. 2C). Since the protein levels of both Wnt5a and ABCG2 in Capan-2 cells were lowest among the tested cell lines, these cells were selected for subsequent experiments. 

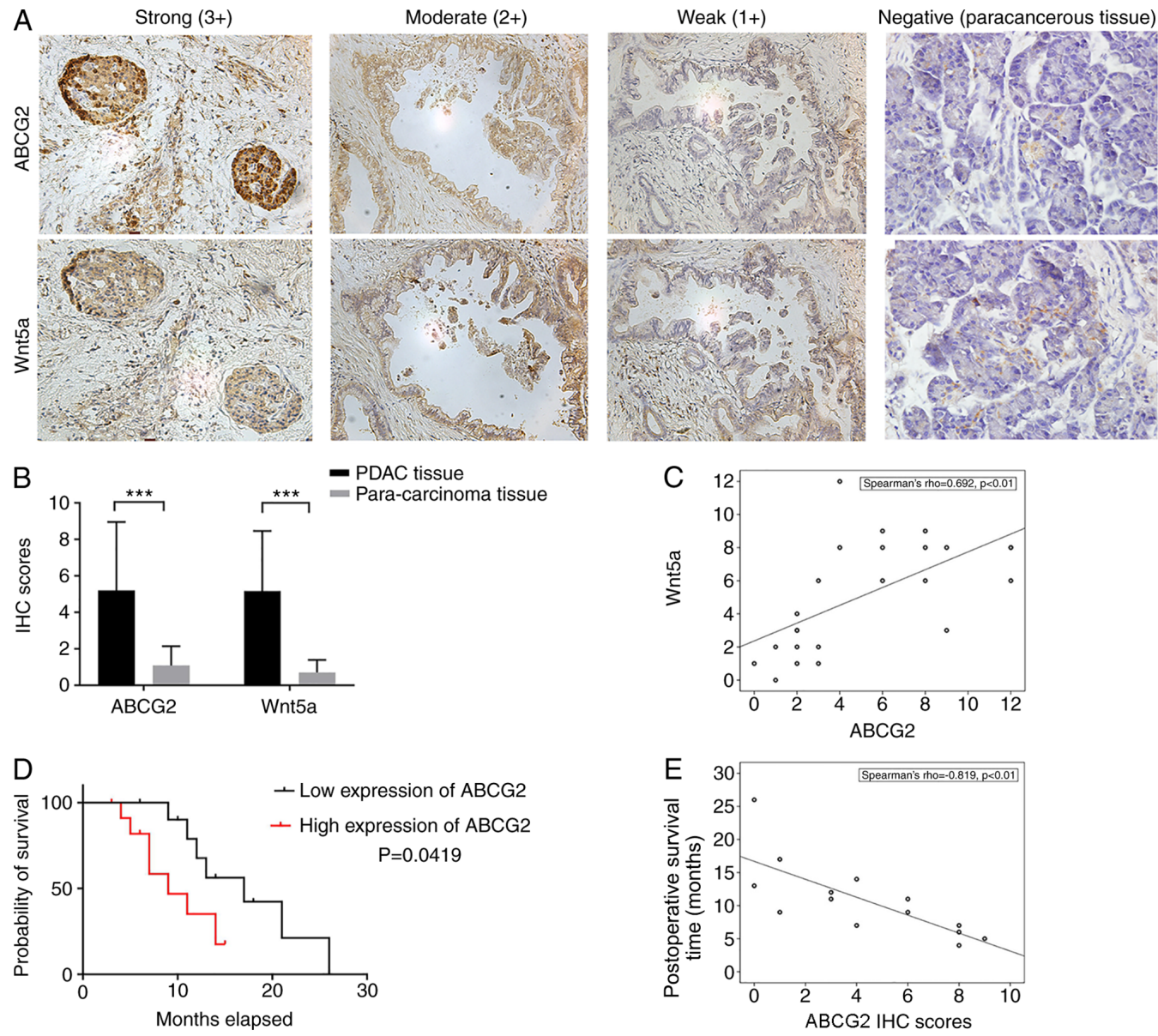

Figure 1. ABCG2 and Wnt5a are expressed in human pancreatic cancer tissue. (A) ABCG2 and Wnt5a IHC staining of PDAC and adjacent healthy tissue samples. $\mathrm{n}=24$. Magnification, $\mathrm{x} 10$. (B) IHC scores for ABCG2 and Wnt5a expression in PDAC and paracarcinoma tissues. ${ }^{* * *} \mathrm{P}<0.001$. (C) Correlation analysis of Wnt5a and ABCG2 IHC scores. n=24. (D) Survival analysis of patients with PDAC according to ABCG2 expression. (E) Correlation analysis of ABCG2 IHC scores and survival time in deceased patients. $\mathrm{n}=14$. ABCG2, ATP binding cassette subfamily G member 2; PDAC, pancreatic ductal adenocarcinoma; IHC, immunohistochemistry.

Recombinant human Wnt5a protein upregulates the expression of ABCG2 in Capan-2 cells. Based on the positive correlation between Wnt5a and ABCG2 expression in colon cancer, lymphoma, glioblastoma, Wilms' tumor (Fig. 2A) and pancreatic cancer cell lines, including Capan-2, it was hypothesized that ABCG2 expression may be regulated by Wnt5a. Thus, to evaluate whether Wnt5a was an upstream regulator of $\mathrm{ABCG} 2$, different concentrations of rhWnt5a protein were added to the culture medium of Capan-2 cells, and changes in ABCG2 protein expression were assessed following treatment. After $48 \mathrm{~h}$ of administration of 100, 200 or $300 \mathrm{ng} / \mathrm{ml} \mathrm{rhWnt5a}$, cells were collected and subjected to western blot analysis. The protein expression levels of ABCG2 increased following rhWnt5a treatment in a dose-dependent manner (Fig. 3), suggesting that the expression of ABCG2 was regulated by Wnt5a.

Wnt5a regulates the expression of $A B C G 2$ gene through FZD7. FZD7 is a receptor proteins in the Wnt pathway. Mining of the 'R2: Genomics Analysis and Visualization Platform' (https://hgserver1.amc.nl/) database identified a positive correlation between Wnt5a expression and FZD7 in pancreatic carcinoma. For the three different datasets [data set of 'Tumor Pancreatic adeno-
carcinoma-TCGA-178-rsem-tcgars', 'Tumor Pancreatic ductal adenocarcinoma-Yeh-132-custom-4hm44k' and 'Tumor Pancreatic ductal adenocarcinoma (ICGC)-Perez-91-complex-ilmnht12v4'], Pearson coefficients between Wnt5a and FZD7 were $0.617\left(\mathrm{P}=5.0 \times 10^{-20}\right)$, $0.417\left(\mathrm{P}=6.68 \times 10^{-7}\right)$ and $0.535\left(\mathrm{P}=4.66 \times 10^{-8}\right)$, respectively (Fig. 4A-a). Furthermore, R2 database demonstrated that FZD7 was positively correlated with ABCG2 expression, with Pearson coefficients between FZD7 and ABCG2 expression levels of $0.163(\mathrm{P}=0.030), 0.290\left(\mathrm{P}=7.5 \times 10^{-4}\right)$ and $0.464\left(\mathrm{P}=3.57 \times 10^{-6}\right)$, respectively, for the same three aforementioned datasets (Fig. 4A-b). These findings indicated that FZD7 may serve a role in regulating the expression of Wnt5a and/or ABCG2 in pancreatic cancer.

Western blot analysis identified that FZD7 was expressed in four different types of pancreatic cancer cell lines (Fig. 4B-a). Moreover, it was found that the siRNA for FZD7 successfully depleted FZD7 expression in Capan-2 cells (Fig. 4B-b). Next, siFZD7 cells were used to examine the effect of FZD7 on Wnt5a-induced upregulation of ABCG2. rhWnt5a $(200 \mathrm{ng} / \mathrm{ml})$ was added to the siFZD7 Capan-2 cells. The cells were collected and western blot analysis performed $48 \mathrm{~h}$ after the treatment. The expression levels of $\beta$-catenin, which are intracellular signal transducers in the Wnt pathway (22), were significantly 

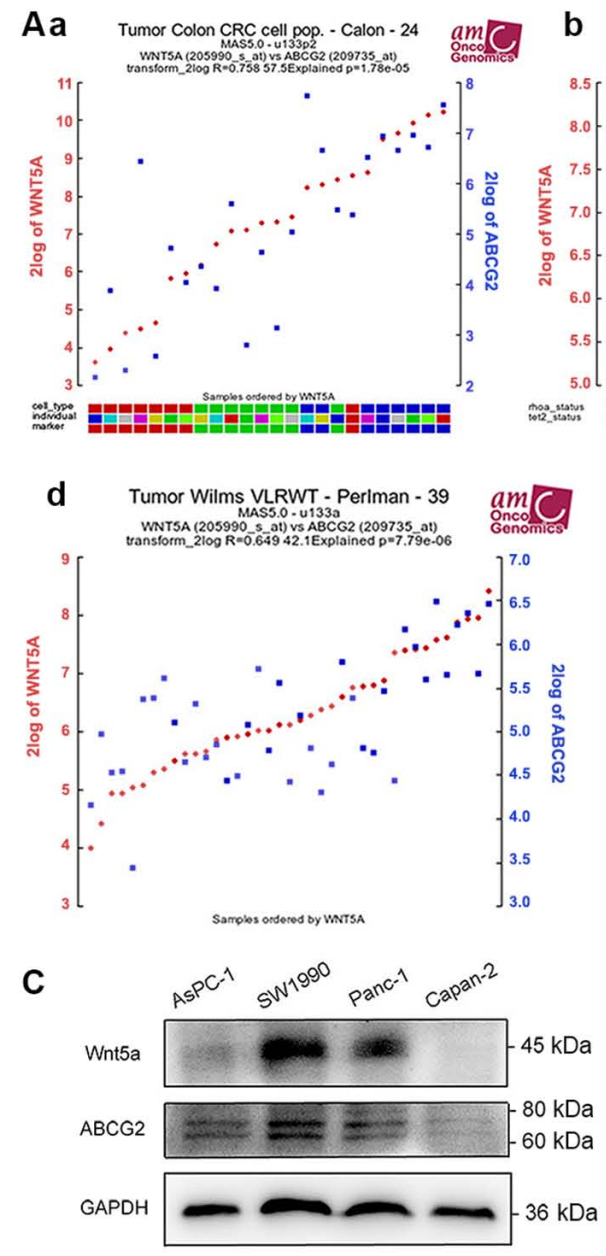
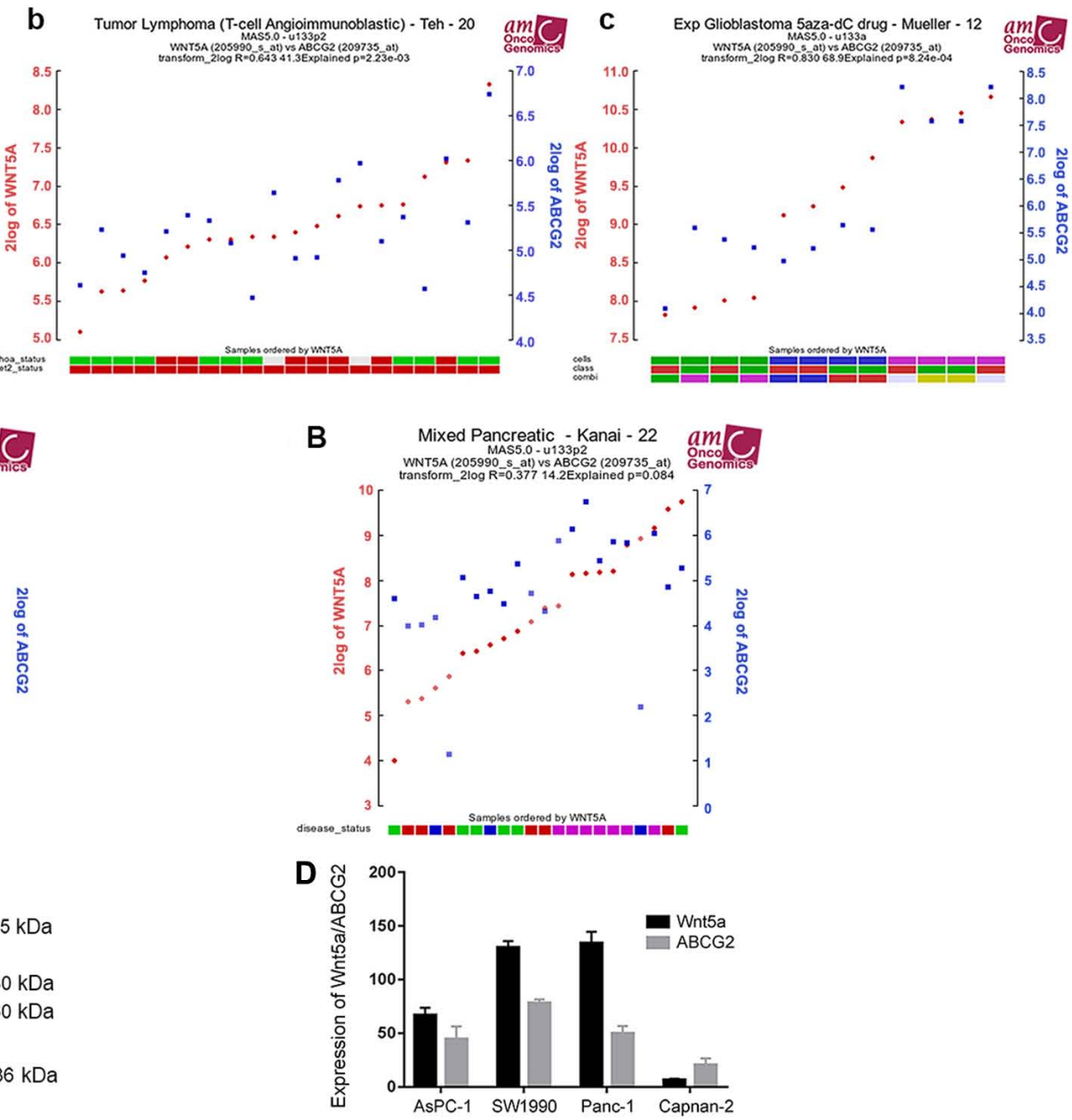

Figure 2. Wnt5a protein expression levels positively correlate with ABCG2. (A) Correlation between Wnt5a and ABCG2 gene expression in (A-a) colon cancer, (A-b) lymphoma, (A-c) glioma and (A-d) nephroblastoma. (B) Correlation between Wnt5a and ABCG2 gene expressions in a variety of pancreatic diseases. (C) Protein expression levels of Wnt5a and ABCG2 in four pancreatic cancer cell lines. (D) Wnt5a and ABCG2 protein expressions in four pancreatic cancer cell lines. ABCG2, ATP binding cassette subfamily G member 2.

A

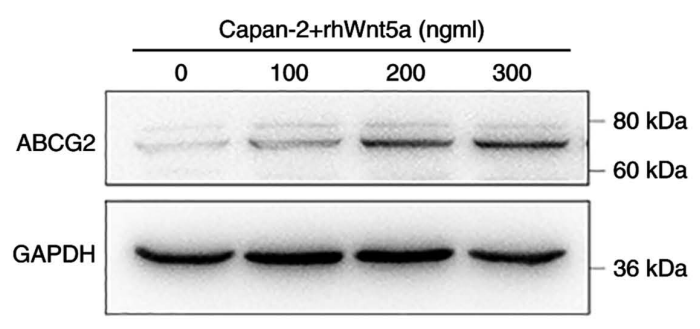

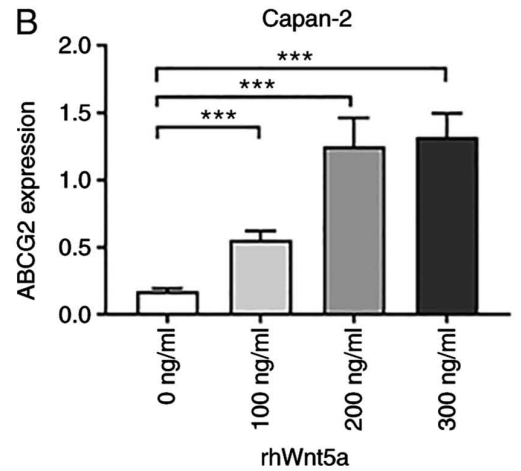

Figure 3. rhWnt5a protein upregulates the expression of ABCG2 in Capan-2 cells. (A) Protein levels of ABCG2 in Capan-2 cells following treatment with rhWnt5a. (B) Quantification of ABCG2 levels normalized to GAPDH. ${ }^{* * *} \mathrm{P}<0.001$. ABCG2, ATP binding cassette subfamily G member 2; rhWnt5a, recombinant human Wnt5a.

lower in the siFZD7 cells compared with control siRNA cells, in the presence of rhWnt5a (Fig. 4C), suggesting that physiological expression of FZD7 is required for the upregulation of ABCG 2 by Wnt5a. However, the overexpression of FZD7 alone did not increase the ABCG2 protein expression (Fig. 4D). These results indicated that FZD7 is necessary, but not sufficient for Wnt5a-induced upregulation of ABCG2 in Capan-2 cells.
Role of FZD7 in Wnt5a-induced Gem resistance in Capan-2 cells. Gem is used to treat a number of cancer types, including pancreatic cancer. MTT assays demonstrated that the $\mathrm{IC}_{50}$ of Gem in Capan-2 cells was increased following the addition of rhWnt5a (Fig. 5A-a), indicating that Wnt5a could directly induce resistance of Capan-2 cells to Gem. To investigate the role of FZD7 in this process, 


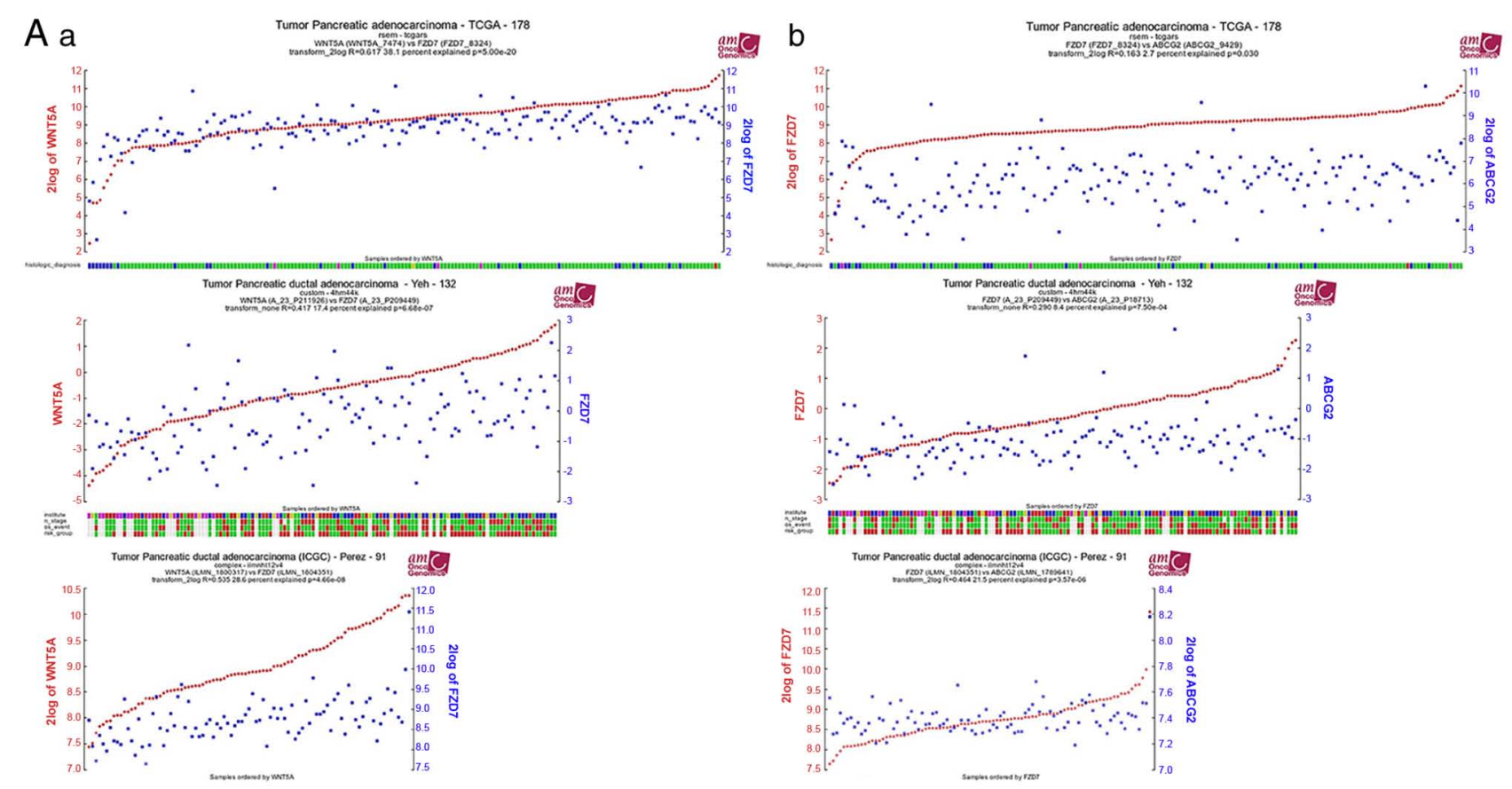

$\mathrm{B}$ a

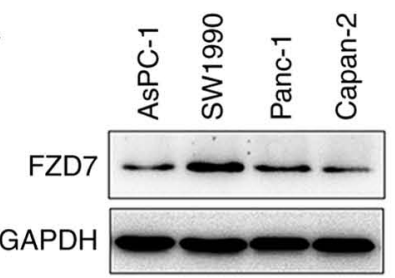

b

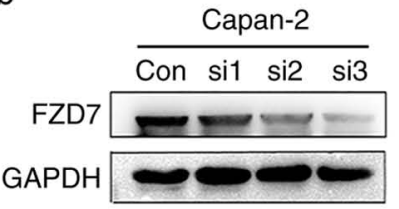

C
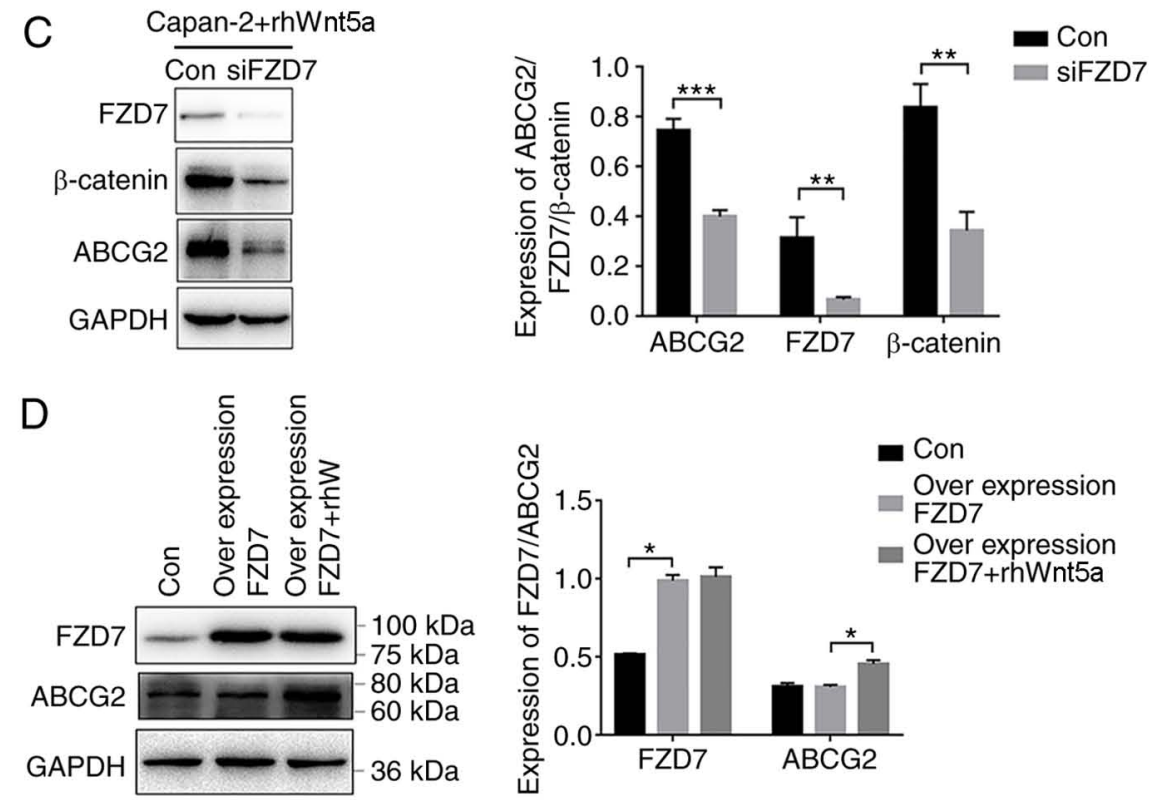

Figure 4. Wnt5a regulates the expression of ABCG2 gene through FZD7. Data sets of 'Tumor Pancreatic adenocarcinoma-TCGA-178-rsem-tcgars', 'Tumor Pancreatic ductal adenocarcinoma-Yeh-132-custom-4hm44k' and 'Tumor Pancreatic ductal adenocarcinoma (ICGC)-Perez-91-complex-ilmnht12v4' in the R2 database demonstrated the correlation between Wnt5a and FZD7 in pancreatic carcinoma (A-a) correlation between FZD7 and ABCG2 in pancreatic carcinoma (A-b). (B-a) Protein levels of FZD7 in four pancreatic cancer cell lines. (B-b) Protein levels of FZD7 after transient transfection of different siRNA molecules targeting FZD7. (C) rhWnt5a does not upregulate ABCG2 and $\beta$-catenin expression following transfection with siFZD7. (D) ABCG2 protein expression following FZD7 overexpression in Capan-2 cells treated with rhWnt5a. ${ }^{*} \mathrm{P}<0.05,{ }^{* *} \mathrm{P}<0.01,{ }^{* * *} \mathrm{P}<0.001$. ABCG2, ATP binding cassette subfamily G member 2; rhWnt5a, recombinant human Wnt5a; FDZ7, Frizzled class receptor 7; siRNA, small interfering RNA; con, control.

FZD7 expression was knocked down using siRNA, or its function was inhibited using the FZD7 inhibitor rhFc (300 $\mathrm{ng} / \mathrm{ml}$ ). While rhWnt5a increased the $\mathrm{IC}_{50}$ value of Gem, the addition of rhFc attenuated this effect (Fig. 5A-b). In addition, in siFZD7 Capan-2 cells, Gem has a lower $\mathrm{IC}_{50}$ compared with control cells (Fig. 5A-c). 
A a

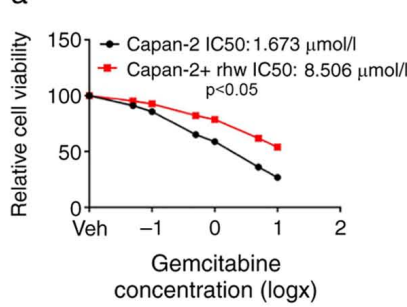

B a

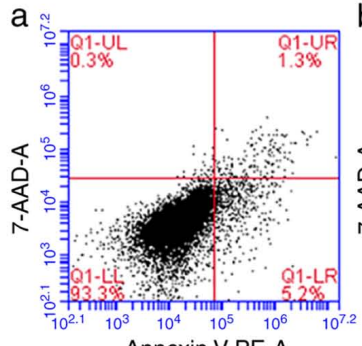

Annexin V-PE-A

C

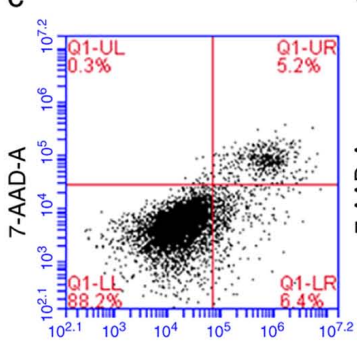

Annexin V-PE-A

C a

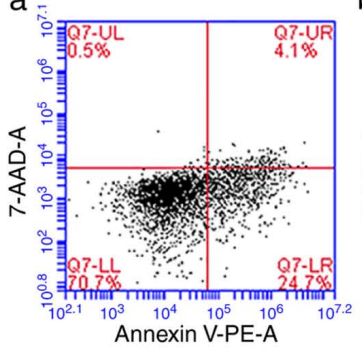

$d$

b . b

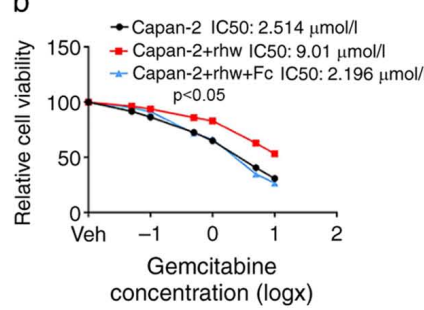

c

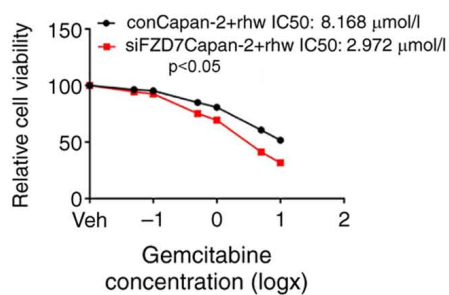

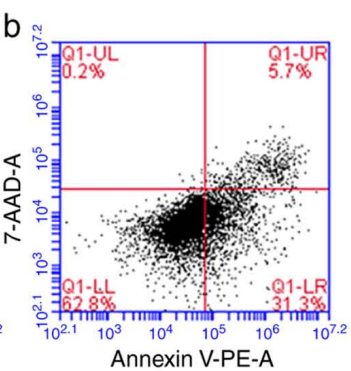

e
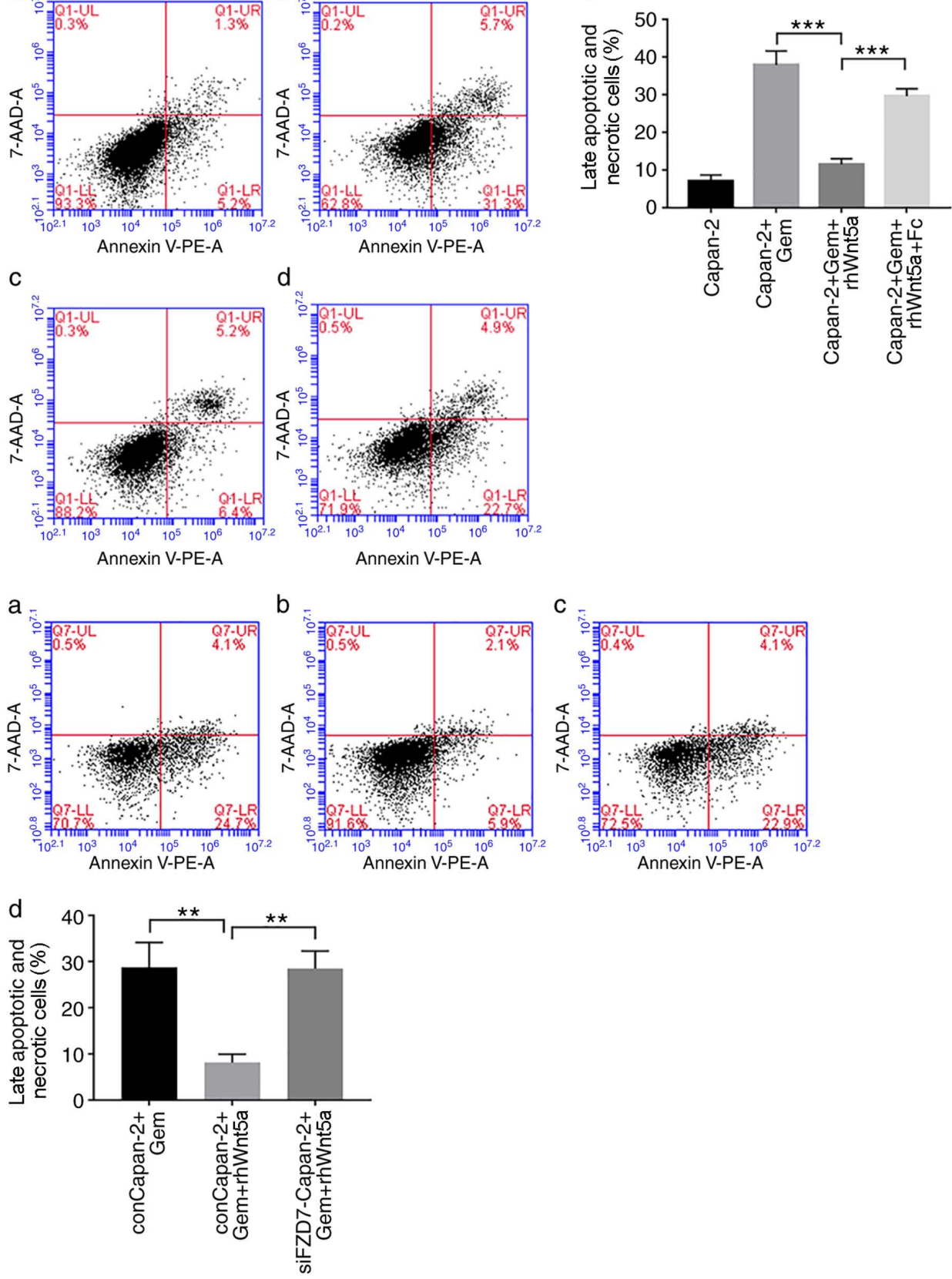

Figure 5. Role of FZD7 in Wnt5a-induced gemcitabine resistance in Capan-2 cells. (A-a) rhWnt5a treatment enhances the IC ${ }_{50}$ of Gem in Capan-2 cells. (A-b) Fc, an inhibitor of FZD7, attenuates the increase in $\mathrm{IC}_{50}$ of Gem induced by rhWnt5a. (A-c) rhWnt5a does not enhance IC50 of Gem in Capan-2 cells siRNA silencing of FZD7 expression. (B-a and B-b) Gem increases the number of late apoptotic and necrotic cells in Capan-2 cells. (B-c) rhWnt5a treatment decreases the number of late apoptotic and necrotic cells following Gem treatment. (B-d) Effect of rhWnt5a on Gem-induced cell death is reduced following Fc treatment. (B-e) Quantification of results. (C-a and C-b) rhWnt5a treatment reduces the number of apoptotic and dead cells in conCapan-2 cells induced by Gem. (C-c) FZD7 siRNA silencing inhibits rhWnt5a-induced Gem resistance. (C-d) Quantification of results. ${ }^{* *} \mathrm{P}<0.01$, ${ }^{* * *} \mathrm{P}<0.001$. rhWnt5a, recombinant human Wnt5a; FDZ7, Frizzled class receptor 7; siRNA, small interfering RNA; con, control; veh, vehicle.

Moreover, the frequency of late apoptotic (lower right quadrant) and necrotic cells (upper right quadrant) induced by Gem (Fig. 5B-a and b) decreased following rhWnt5a treatment (Fig. 5B-c), compared with untreated cells. However, 

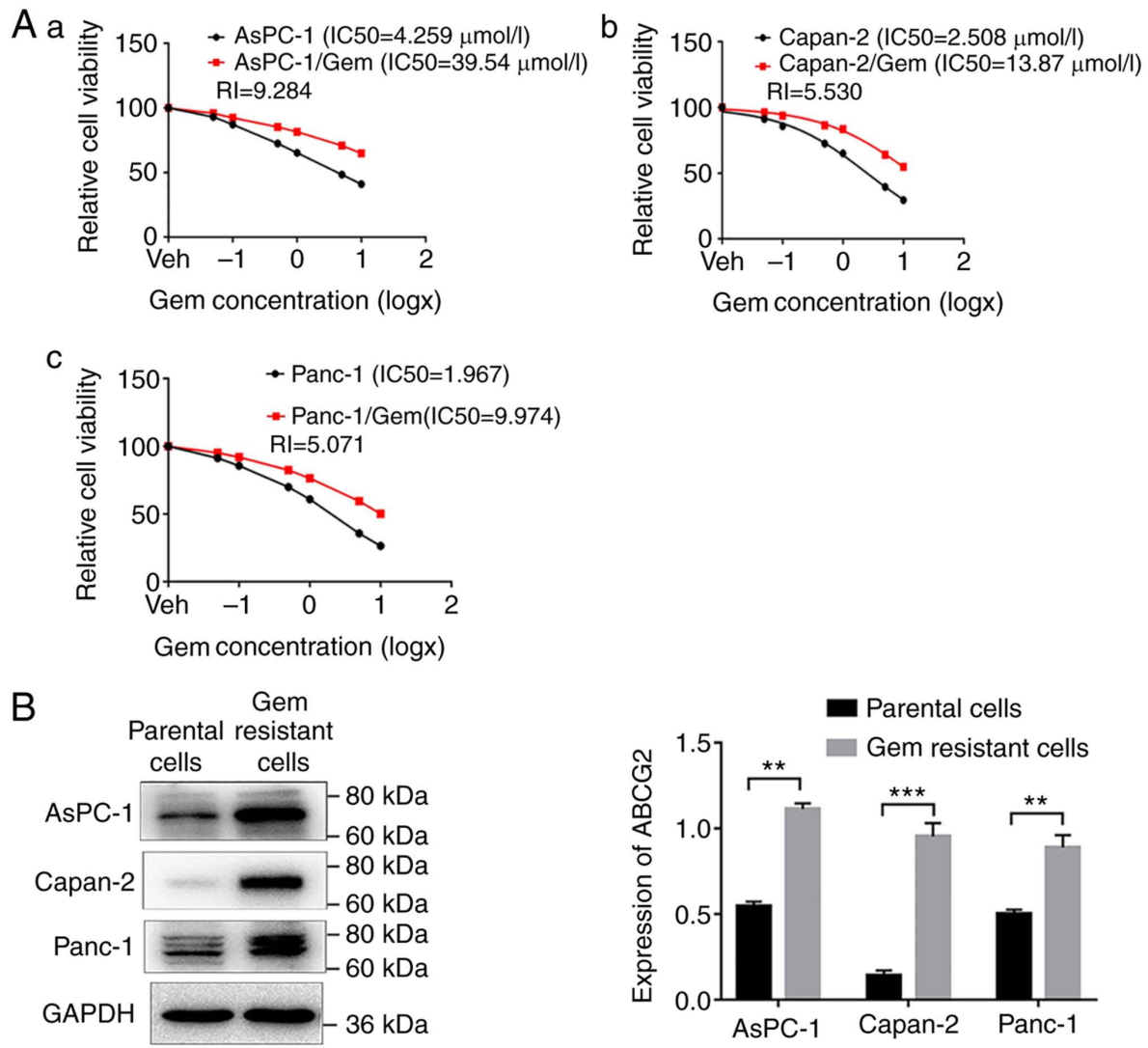

Figure 6. Gem-resistant cell lines express high levels of ABCG2. (A) $\mathrm{IC}_{50}$ of 3 the Gem-resistant cell lines (A-a) AsPC-1/Gem, (A-b) Capan-2/Gem and (A-c) and Panc-1/Gem significantly increased, compared with parental cells. (B) ABCG2 protein expression levels in the three Gem-resistant cell lines. ${ }^{* *} \mathrm{P}<0.01,{ }^{* * *} \mathrm{P}<0.001$. ABCG2, ATP binding cassette subfamily G member 2; Gem, gemcitabine; RI, resistance index ( $=\mathrm{IC}_{50}$ of normal cells/ $/ \mathrm{IC}_{50}$ of Gem resistant cells).

treatment with rhFc reduced the frequency of apoptotic and necrotic cells, compared with cells treated with rhWnt5a alone (Fig. 5B-d and e). Moreover, while rhWnt5a decreased the number of late apoptotic and dead cells induced by Gem in control siRNA cells (Fig. 5C-a and b), no such effects were observed in the FZD7 siRNA cells (Fig. 5C-c and d). Collectively, these data suggested that FZD7 may be a key factor for the induction of Gem resistance via Wnt5a in pancreatic cancer cells.

Gem-resistant cells express higher levels of ABCG2 compared with parental cells. To determine whether high ABCG2 expression was associated with Gem resistance in different cell lines, pancreatic carcinoma cell lines resistant to Gem (AsPC-1/Gem, Capan-2/Gem and Panc-1/Gem) were established using a low concentration of Gem continuously. Next, the $\mathrm{IC}_{50}$ of Gem was measured using an MTT assay in these cell lines and compared with the $\mathrm{IC}_{50}$ in the parental cells (Fig. 6A). The $\mathrm{IC}_{50}$ of Gem was increased from 4.259 , 2.508 and $1.967 \mu \mathrm{M}$ to $39.54,13.87$ and $9.974 \mu \mathrm{M}$, respectively, in AsPC-1/Gem, Capan-2/Gem and Panc-1/Gem cells as compared with their parent cells (Fig. 6A), indicating successful establishment of Gem-resistant pancreatic cancer cell lines. Moreover, the drug-resistant cells expressed significantly higher levels of ABCG2 compared with the parental cells (Fig. 6B), suggesting that upregulation of $\mathrm{ABCG} 2$ may contribute to Gem resistance of pancreatic cancer cells.

\section{Discussion}

Pancreatic cancer is associated with poor prognosis, and the lack of effective chemotherapeutic drugs has been a challenge for the treatment of pancreatic cancer. For instance, one such issue for chemotherapy is drug resistance. Gem is one of few drugs used for first-line chemotherapy for pancreatic cancer. But it is effective in only $23.8 \%$ of PDAC cases (22), and development of Gem chemoresistance serves an important role in this ineffectiveness (23). The present study aimed to elucidate the molecular mechanisms underlying Gem resistance in order to provide a novel therapy strategy for PDAC. It has been reported that the ABC-transporter superfamily proteins serve important roles in MDR (6). And the increase in the protein expression of ABCG2 has been shown to be required for Gem resistance in pancreatic cancer cells (10). This finding is consistent with the present results, which indicated that the protein expression of ABCG2 was significantly higher in three different Gem-resistant pancreatic cancer cell lines, compared with parental control cells. Moreover, the IHC staining of 24 PDAC and adjacent tissue samples demonstrated that high expression of ABCG2 correlated with poor prognosis. Therefore, it would be beneficial to examine whether the poor prognosis resulting from the high ABCG2 expression was associated with increased drug-resistance in vivo.

To identify the upstream regulators of ABCG2 expression, the present study focused on Wnt signaling proteins, as previous studies have reported the possible function of the 
Wnt signaling pathway in the regulation of ABCG2 expression; however, most studies were performed in cancer types other than pancreatic cancer (11-14). Among the numerous Wnt proteins, the current study focused on Wnt5a, as it is considered a mediator of chemoresistance (15). To the best of the authors' knowledge, no other Wnt family members have been reported to regulate ABCG2. Furthermore, the inhibition of Wnt5a increases the sensitivity of pancreatic cancer cells to drug treatment in vitro and in vivo (18). In the current study, a positive correlation between Wnt5a and ABCG2 gene expression levels was identified using the R2 database. In addition, Wnt5a expression was positively correlated with ABCG2 expression in the 24 PDAC samples and in four different PDAC cell lines. As Wnt5a is a secreted protein that affects cells in an autocrine or paracrine manner, and most PDAC cell lines have the capacity to respond to exogenous Wnt stimulation (24), rhWnt5a was used to treat Capan-2 cells in order to assess its effect on ABCG2 expression. An increase in ABCG2 protein expression in Capan-2 cells was observed after Wnt5a treatment, supporting the hypothesis that Wnt5a may be an upstream regulator of $\mathrm{ABCG} 2$ in pancreatic cancer cells.

Wnt proteins are series of secretory proteins that bind to Frizzle receptors on cell membranes in an autocrine or paracrine manner and activate intracellular molecular cascade (classical pathway or non-classical pathway) (24). For instance, once a classical pathway is active, there is an accumulation of un-phosphorylated $\beta$-catenin in the cytosol, which can translocate to the nucleus, interacting with $\mathrm{T}$ cell-specific factor or lymphoid enhancer-binding factor to activate the Wnt target genes, such as c-Myc and cyclin D1 (25). The Wnt protein act as ligands, whether from paracrine or autocrine of peripheral cells, to effective bind to Frizzle receptors, and is key for the activation and biological function of the Wnt signaling pathway. Therefore, the present study further investigated which type of Frizzle receptor could be involved in the regulation of ABCG2 expression. The data extracted from the R2 database suggested that Wnt5a protein expression correlated with the Wnt receptor FZD7. The expression of ABCG2 was induced by Wnt5a in a dose-dependent manner. The Wnt5a-mediated upregulation of ABCG5 was inhibited by the Fzd7 knockdown, suggesting that Wnt5a regulatesd the expression of ABCG2 through Fzd7. It has been previously reported that Wnt5a and FZD7 are highly expressed in melanoma, and that Wnt5a enhances the proliferation and viability of melanoma cells through FZD7 (26). Thus, the current study used a FDZ7 inhibitor and FDZ7 siRNA to inhibit the function or knockdown the expression of FDZ7. Subsequently, the effect of these treatments on the expression of $\mathrm{ABCG} 2$ was evaluated in pancreatic cells. Inhibition of FDZ7 function and FDZ7 knockdown both attenuated Wnt5a-induced upregulation of ABCG2, as well as the resistance of pancreatic cells to Gem, indicating a critical role for FZD7 in the regulation of ABCG2 and drug resistance in pancreatic cancer cells. Interestingly, FZD7 alone was not able to induce Gem resistance, suggesting that FZD7 was necessary but not sufficient for induction of drug resistance in pancreatic cancer cells.

A subpopulation of tumor cells with self-renewal and multi-lineage differentiation capacity, defined as cancer stem cells (CSCs), has been implicated in tumor resistance to therapy, as well as recurrence, invasiveness, metastasis and reduced patient survival time (27-29). Cancer cells with a stem cell phenotype are more resistant to anti-cancer drugs and express higher levels of ABCG2 compared with those without stem cell phenotype (29-31). The activation of ABCG2 (32) or ABCB1 (31) is considered to be one of the mechanisms for drug resistance of CSCs. For instance, the presence of ABCG2 in certain populations of CSCs increases the likelihood of resistance to various anticancer drugs $(33,34)$. Based on the fact that ABCG2 is highly expressed in certain CSC cells (29), ABCG2 was proposed as one of the phenotypes of CSCs (35). Recently, Sasaki et al (36) isolated ABCG2 positive pancreatic cancer cells in 3D culture conditions that had stemness characteristics and anti-cancer drug resistance. Therefore, it would be interesting to determine whether ABCG2 is required for maintaining stemness of pancreatic CSCs and whether this accounts for the resistance of pancreatic cancer cells to anticancer drugs.

In conclusion, proteins in the Wnt pathway, such as Wnt5a and FZD7, serve an important role in regulating the expression of ABCG2, as well as in the anticancer drug resistance of pancreatic cancer cells.

\section{Acknowledgements}

Not applicable.

\section{Funding}

This study was supported by the National Natural Science Foundation of China (grant no. 81572360).

\section{Availability of data and materials}

The datasets used and/or analyzed during the current study are available from the corresponding author on reasonable request. The bioinformatics datasets generated and/or analyzed during the current study are available in the 'R2: Genomics Analysis and Visualization Platform' repository (https://hgserverl.amc. $\mathrm{nl} /$ ).

\section{Authors' contributions}

ZBZ performed the majority of experiments and drafted the manuscript. SG performed some of the experiments, as well as conducted data statistical analysis and English translation modification. YHX and CHZ designed the project, performed the interpretation of patient data regarding the PDAC and gave final approval of the version to be published. All authors read and approved the final manuscript.

\section{Ethics approval and consent to participate}

This study was approved by The Ethical Committee of The First Hospital of China Medical University [approval no. (2015)100]. Written informed consent was obtained from all patients.

\section{Patient consent for publication}

Not applicable. 


\section{Competing interests}

The authors declare that they have no competing interests.

\section{References}

1. Ryan DP, Hong TS and Bardeesy N: Pancreatic adenocarcinoma N Engl J Med 371: 1039-1049, 2014.

2. Matano E, Tagliaferri P, Libroia A, Damiano V, Fabbrocini A, De Lorenzo S and Bianco AR: Gemcitabine combined with continuous infusion 5-fluorouracil in advanced and symptomatic pancreatic cancer: A clinical benefit-oriented phase II study. Br J Cancer 82: 1772-1775, 2000.

3. Xu M, Li L, Liu Z, Jiao Z, Xu P, Kong X, Huang H and Zhang Y ABCB2 (TAP1) as the downstream target of SHH signaling enhances pancreatic ductal adenocarcinoma drug resistance. Cancer Lett 333: 152-158, 2013.

4. Chen M, Xue X, Wang F, An Y, Tang D, Xu Y, Wang H, Yuan Z, Gao W, Wei J, Zhang J and Miao Y: Expression and promoter methylation analysis of ATP-binding cassette genes in pancreatic cancer. Oncol Rep 27: 265-269, 2012.

5. Hopper-Borge E, Xu X, Shen T, Shi Z, Chen ZS and Kruh GD Human multidrug resistance protein 7 (ABCC10) is a resistance factor for nucleoside analogues and epothilone B. Cancer Res 69 178-184, 2009.

6. Szakacs G, Paterson JK, Ludwig JA, Booth-Genthe C and Gottesman MM: Targeting multidrug resistance in cancer. Nat Rev Drug Discov 5: 219-234, 2006.

7. Binkhathlan Z and Lavasanifar A: P-glycoprotein inhibition as a therapeutic approach for overcoming multidrug resistance in cancer: Current status and future perspectives. Curr Cancer Drug Targets 13: 326-346, 2013.

8. Choudhuri S and Klaassen CD: Structure, function, expression, genomic organization, and single nucleotide polymorphisms of human ABCB1 (MDR1), ABCC (MRP), and ABCG2 (BCRP) efflux transporters. Int J Toxicol 25: 231-259, 2006.

9. Gatti L, Beretta GL, Cossa G, Zunino F and Perego P: ABC transporters as potential targets for modulation of drug resistance. Mini Rev Med Chem 9: 1102-1112, 2009.

10. Hsu MC, Pan MR, Chu PY, Tsai YL, Tsai CH, Shan YS, Chen LT and Hung WC: Protein arginine methyltransferase 3 enhances chemoresistance in pancreatic cancer by methylating hnRNPA1 to increase ABCG2 Expression. Cancers (Basel) 11: 8, 2018.

11. Vesel M, Rapp J, Feller D, Kiss E, Jaromi L, Meggyes M, Miskei G, Duga B, Smuk G, Laszlo T and Karner I: ABCB1 and $\mathrm{ABCG} 2$ drug transporters are differentially expressed in non-small cell lung cancers (NSCLC) and expression is modified by cisplatin treatment via altered Wnt signaling. Respir Res 18 : 52, 2017.

12. Chen B, Zhang D, Kuai J, Cheng M, Fang X and Li G: Upregulation of $\mathrm{miR}-199 \mathrm{a} / \mathrm{b}$ contributes to cisplatin resistance via $\mathrm{Wnt} / \beta$-catenin-ABCG2 signaling pathway in ALDHA $1^{+}$colorectal cancer stem cells. Tumor Biol 39: 1-14, 2017.

13. Martins-Neves SR, Paiva-Oliveira DI, Wijers-Koster PM, Abrunhosa AJ, Fontes-Ribeiro C, Bovée JV, Cleton-Jansen AM and Gomes CM: Chemotherapy induces stemness in osteosarcoma cells through activation of Wnt/ $\beta$-catenin signaling. Cancer Lett 370: 286-295, 2016.

14. Spee B, Carpino G, Schotanus BA, Katoonizadeh A, Vander Borght S, Gaudio E and Roskams T: Characterisation of the liver progenitor cell niche in liver diseases: Potential involvement of Wnt and Notch signaling. Gut 59: 247-257, 2010.

15. Peng C, Zhang X, Yu H, Wu D and Zheng J: Wnt5a as a predictor in poor clinical outcome of patients and a mediator in chemoresistance of ovarian cancer. Int J Gynecol Cancer 21: 280-288, 2011.

16. Hung TH, Hsu SC, Cheng CY, Choo KB, Tseng CP, Chen TC, Lan YW, Huang TT, Lai HC, Chen CM and Chong KY: Wnt5a regulates $\mathrm{ABCB} 1$ expression in multidrug-resistant cancer cells through activation of the non-canonical PKA/ $\beta$-catenin pathway. Oncotarget 5: 12273-12290, 2014.

17. Cao J, Wang Q, Wu G, Li S and Wang Q: miR-129-5p inhibits Gemcitabine resistance and promotes cell apoptosis of bladder cancer cells by targeting Wnt5a. Int Urol Nephrol 50: 1811-1819, 2018.
18. Ying J, Li H, Yu J, Ng KM, Poon FF, Wong SC, Chan AT, Sung JJ and Tao Q: WNT5A exhibits tumor-suppressive activity through antagonizing the Wnt/beta-catenin signaling, and is frequently methylated in colorectal cancer. Clin Cancer Res 14: 55-61, 2008.

19. Jiang Z, Zhou C, Cheng L, Yan B, Chen K, Chen X, Zong L, Lei J, Duan W, Xu Q, et al: Inhibiting YAP expression suppresses pancreatic cancer progression by disrupting tumor-stromal interactions. J Exp Clin Cancer Res 37: 69, 2018.

20. McDermott M, Eustace AJ, Busschots S, Breen L, Crown J, Clynes M, O'Donovan N and Stordal B: In vitro development of chemotherapy and targeted therapy drug-resistant cancer cell lines: A Practical Guide with Case Studies. Front Oncol 6: 40, 2014.

21. Qiu X, Jiao J, Li Y and Tian T: Overexpression of FZD7 promotes glioma cell proliferation by upregulating TAZ. Oncotarget 7: 85987-85999, 2016.

22. Liang C, Shi S, Meng Q, Liang D, Ji S, Zhang B, Qin Y, Xu J, $\mathrm{Ni} Q$ and Yu X: Complex roles of the stroma in the intrinsic resistance to gemcitabine in pancreatic cancer: Where we are and where we are going. Exp Mol Med 49: e406, 2017.

23. Amrutkar $M$ and Gladhaug IP. Pancreatic Cancer Chemoresistance to Gemcitabine. Cancers (Basel) 9: 157, 2017.

24. Arensman MD, Kovochich AN, Kulikauskas RM, Lay AR, Yang PT, Li X, Donahue T, Major MB, Moon RT, Chien AJ and Dawson DW: WNT7B mediates autocrine Wnt $/ \beta$-catenin signaling and anchorage-independent growth in pancreatic adenocarcinoma.Oncogene 33: 899-908, 2014.

25. Gordon MD and Nusse R: Wnt signaling: Multiple pathways, multiple receptors, and multiple transcription factors. J Biol Chem 281: 22429-22433, 2006

26. Anastas JN, Kulikauskas RM, Tamir T, Rizos H, Long GV, von Euw EM, Yang PT, Chen HW, Haydu L, Toroni RA, et al: WNT5A enhances resistance of melanoma cells to targeted BRAF inhibitors. J Clin Invest 124: 2877-2890, 2014.

27. Frank NY, Schatton T and Frank MH: The therapeutic promise of the cancer stem cell concept. J Clin Invest 120: 41-50, 2010.

28. Todaro M,Francipane MG, Medema JP and Stassi G: Colon cancer stem cells: Promise of targeted therapy. Gastroenterology 138: 2151-2162, 2010

29. Crea F, Danesi R and Farrar WL: Cancer stem cell epigenetics and chemoresistance. Epiqenomics 1: 63-79, 2009.

30. Wang XQ, Ongkeko WM, Chen L, Yang ZF, Lu P, Chen KK, Lopez JP, Poon RT and Fan ST: Octamer 4 (Oct4) mediates chemotherapeutic drug resistance in liver cancer cells through a potential Oct4-AKT-ATP-binding cassette G2 pathway. Hepatology 52: 528-539, 2010.

31. Song KH, Choi CH, Lee HJ, Oh SJ, Woo SR, Hong SO, Noh KH, Cho H, Chung EJ, Kim JH, et al: HDAC1 upregulation by NANOG promotes multidrug resistance and a stem-like phenotype in immune edited tumor cells. Cancer Res 77: 5039-5053, 2017.

32. Jiang H, Xiong W, Chen L, Lv Z, Yang C and Li Y: Knockdown of the long noncoding RNA HOTTIP inhibits cell proliferation and enhances cell sensitivity to cisplatin by suppressing the Wnt/ $\beta$-catenin pathway in prostate cancer. J Cell Biochem 120: 8965-8974, 2019.

33. An Y and Ongkeko WM: ABCG2: The key to chemoresistance in cancer stem cells? Expert Opin Drug Metab Toxicol 5: 1529-1542, 2009.

34. Ding XW, Wu JH and Jiang CP: ABCG2: A potential marker of stem cells and novel target in stem cell and cancer therapy. Life Sci 86: 631-637, 2010.

35. Bisson I and Prowse DM: WNT signaling regulates self-renewal and differentiation of prostate cancer cells with stem cell characteristics. Cell Res 19: 683-697, 2009.

36. Sasaki N, Ishiwata T, Hasegawa F, Michishita M, Kawai H, Matsuda Y, Arai T, Ishikawa N, Aida J, Takubo K and Toyoda M: Stemness and anti-cancer drug resistance in ATP-binding cassette subfamily $\mathrm{G}$ member 2 highly expressed pancreatic cancer is induced in 3D culture conditions. Cancer Sci 109: $1135-1146,2018$.

This work is licensed under a Creative Commons Attribution-NonCommercial-NoDerivatives 4.0 International (CC BY-NC-ND 4.0) License. 